\title{
Influence of Postoperative Surgical Complications After Gastrectomy on Body Weight and Body Composition Changes in Patients With Gastric Cancer
}

\author{
TORU AOYAMA ${ }^{1,2^{*}}$, TAKAKI YOSHIKAWA ${ }^{1,2^{*}}$, YUKIO MAEZAWA ${ }^{1,2}$, KENKI SEGAMI $^{1,2}$, KAZUKI KANO $^{1,2}$, \\ MASAKATSU NUMATA ${ }^{1,2}$, TAKANOBU YAMADA ${ }^{1,2}$, HIROSHI TAMAGAWA $^{2}$, HIROHITO FUJIKAWA $^{1,2}$, \\ KEISUKE KOMORI ${ }^{2}$, TSUTOMU HAYASHI ${ }^{1,2}$, TSUTOMU SATO ${ }^{1,2}$, NORIO YUKAWA ${ }^{2}$, YASUSHI RINO ${ }^{2}$, \\ MUNETAKA MASUDA ${ }^{2}$, TAKASHI OGATA ${ }^{1}$, HARUHIKO CHO $^{1}$ and TAKASHI OSHIMA ${ }^{1,2}$ \\ ${ }^{1}$ Department of Gastrointestinal Surgery, Kanagawa Cancer Center, Kanagawa, Japan; \\ ${ }^{2}$ Department of Surgery, Yokohama City University, Yokohama, Japan
}

\begin{abstract}
Background: Body weight, especially lean body mass, significantly decreases after gastrectomy. Postoperative surgical complications are a major risk factor for changes in body weight and body composition after gastrectomy. However, the influence of postoperative surgical complications after gastrectomy on body weight and body composition changes remains unclear. Patients and Methods: This retrospective study examined patients who underwent curative surgery for gastric cancer between May 2010 and February 2017. Their body weight and composition were evaluated by a bioelectrical impedance analyzer within 1 week before surgery, and at 1 week, 1 month and 3 months after surgery. Patients were classified as those with surgical complications and those without. Results: Eight hundred and eighty-eight patients (156 in the group with complications and 732 in the group without) were entered in the present study. When comparing the two groups, the patients' background and surgical factors significantly differed, while the pathological findings were similar. The body weight losses at 1 week, 1 month, and 3 months after surgery were $3.8 \%, 7.0 \%$, and $10.4 \%$, respectively, in those with complications, and $3.3 \%, 5.6 \%$, and $6.8 \%$, respectively, in the group without, with p-values of 0.001 , 0.002 , and 0.001 , respectively. The corresponding lean body mass losses were $3.7 \%, 6.5 \%$, and $6.8 \%$, and $3.2 \%, 4.2 \%$, and $3.5 \%$, respectively, with p-values of $0.001,0.001$, and 0.001 ,
\end{abstract}

\footnotetext{
*These Authors contributed equally to this study.

Correspondence to: Toru Aoyama, Department of Surgery, Yokohama City University, 3-9 Fukuura, Kanazawa-ku, Yokohama 236-0004, Japan. Tel: +81 0457872800, e-mail: t-aoyama@lilac.plala.or.jp

Key Words: Gastric cancer, surgical complications, body weight loss, lean body mass.
}

respectively. Conclusion: Decreases in body weight and lean body mass after gastrectomy were more serious in the patients with surgical complications than in those without. To maintain body weight and lean body mass in patients with surgical complications, additional care or treatments are needed.

Gastric cancer is the fourth most common human malignant disease and the second-most frequent cause of cancer-related death worldwide (1). Complete resection is essential for the cure of gastric cancer $(2,3)$. However, the surgical complication rate after gastrectomy with lymph node dissection has been reported to range from $15-30 \%$ (4-6). Previous studies have shown that the development of surgical complications increased the risk of poor overall survival and tumor recurrence in gastric cancer $(7,8)$.

Body composition changes are common problems after gastrectomy for gastric cancer $(9,10)$. Previous studies have shown that body composition changes reduced the nutritional status, postoperative quality of life, and compliance with adjuvant chemotherapy (11-13). Surgical complications after gastrectomy also affect postoperative body composition changes. Body composition changes after gastrectomy might be much more substantial and last longer in patients with postoperative surgical complications than in those without. If body composition changes after gastrectomy are indeed much more substantial in patients with postoperative surgical complications than in those without such complications, additional care or treatments might be needed. However, few reports have evaluated this issue.

The aim of the present study was to evaluate body composition changes after gastrectomy using a bioelectrical impedance analyzer and to compare the degree and duration of body composition changes between patients with postoperative surgical complications after gastrectomy and those without. 
Table I. Comparison of patient background characteristics.

\begin{tabular}{|c|c|c|c|c|}
\hline Characteristic & $\begin{array}{l}\text { All cases } \\
\mathrm{N}=888\end{array}$ & $\begin{array}{l}\text { Without complications } \\
\qquad \mathrm{N}=732\end{array}$ & $\begin{array}{l}\text { With complications } \\
\qquad \mathrm{N}=156\end{array}$ & $p$-Value \\
\hline \multicolumn{5}{|l|}{ Age, years } \\
\hline Median (range) & $68(27-90)$ & $68(27-90)$ & $71(45-88)$ & 0.002 \\
\hline \multicolumn{5}{|l|}{ Gender, n (\%) } \\
\hline Male & $595(67.0)$ & $472(64.5)$ & $123(78.8)$ & \multirow[t]{2}{*}{0.001} \\
\hline Female & $293(33.0)$ & $260(35.5)$ & $33(21.2)$ & \\
\hline \multicolumn{5}{|l|}{ ASA-PS } \\
\hline 1 & $201(22.6)$ & $177(24.2)$ & $24(15.4)$ & \multirow[t]{3}{*}{0.026} \\
\hline 2 & $671(75.6)$ & $544(74.3)$ & $127(81.4)$ & \\
\hline 3 & $16(1.8)$ & $11(1.5)$ & $5(0.2)$ & \\
\hline \multicolumn{5}{|c|}{ Total body weight, $\mathrm{kg}$} \\
\hline Median (range) & $58.5(31.8-102.5)$ & $58.0(31.8-102.5)$ & $61.6(35.3-89.5)$ & 0.011 \\
\hline \multicolumn{5}{|l|}{ Lean body mass, $\mathrm{kg}$} \\
\hline Median (range) & $46.1(27.2-67.0)$ & $45.6(27.2-67.0)$ & $48.0(29.5-61.5)$ & 0.010 \\
\hline \multicolumn{5}{|l|}{ Body mass index } \\
\hline Median (range) & $22.3(13.9-35.6)$ & $22.0(13.9-35.6)$ & $22.9(15.4-33.7)$ & 0.011 \\
\hline \multicolumn{5}{|l|}{ Tumor site, n (\%) } \\
\hline Upper third & $202(22.7)$ & $148(20.2)$ & $54(34.6)$ & \multirow[t]{3}{*}{0.001} \\
\hline Middle third & $429(48.3)$ & $365(49.9)$ & $64(41.0)$ & \\
\hline Lower third & $257(29.0)$ & $219(29.9)$ & $38(24.4)$ & \\
\hline \multicolumn{5}{|c|}{ Clinical $\mathrm{T}$ factor, $\mathrm{n}(\%)$} \\
\hline $\mathrm{T} 1-\mathrm{T} 2$ & $576(64.9)$ & $490(66.9)$ & $86(55.1)$ & \multirow[t]{2}{*}{0.005} \\
\hline $\mathrm{T} 3-\mathrm{T} 4$ & $312(35.1)$ & $242(33.1)$ & $70(44.9)$ & \\
\hline \multicolumn{5}{|c|}{ Clinical $\mathrm{N}$ factor, $\mathrm{n}(\%)$} \\
\hline Negative & $704(79.3)$ & $592(80.9)$ & $112(71.8)$ & \multirow[t]{2}{*}{0.011} \\
\hline Positive & $184(20.7)$ & $140(19.1)$ & $44(28.2)$ & \\
\hline \multicolumn{5}{|l|}{ Co-morbidity, n (\%) } \\
\hline Hypertension & $410(46.2)$ & $322(44.0)$ & $88(56.4)$ & 0.036 \\
\hline Diabetes mellitus & $107(12.0)$ & $83(11.3)$ & $24(15.4)$ & 0.224 \\
\hline COPD & $178(20.0)$ & $144(19.7)$ & $34(21.8)$ & 0.979 \\
\hline \multicolumn{5}{|c|}{ Smoking habit, n (\%) } \\
\hline Yes & $449(50.6)$ & $351(48.0)$ & $98(62.8)$ & \multirow[t]{2}{*}{0.018} \\
\hline No & $439(49.4)$ & $381(52.0)$ & $58(37.2)$ & \\
\hline
\end{tabular}

ASA-PS, American Society of Anesthesiologists physical status; COPD, chronic obstructive pulmonary disease.

\section{Patients and Methods}

Patients. This was a retrospective cohort study. Patients' records were retrieved from a prospectively collected database of Kanagawa Cancer Center from May 2010 to February 2017. The inclusion criteria were as follows: curative gastrectomy with lymph node dissection for gastric cancer was performed as the primary treatment, R0 resection was achieved, no weight loss over $15 \%$ before surgery was experienced, and a body composition analysis was performed within 1 week before surgery, and at 1 week, 1 month and 3 months after surgery.

Surgical procedure. All patients underwent distal or total gastrectomy with nodal dissection for gastric cancer. In principle, D1 or D1 plus lymphadenectomy is indicated for cT1N0 tumors, and D2 is applied for $\mathrm{cN}+$ or cT2-T4 tumors regardless of the approach. Spleenpreserving D2 total gastrectomy was permitted in this study.

Perioperative care. The patients received the enhanced recovery after surgery (ERAS) protocol after gastrectomy. The details of this protocol have been previously reported $(14,15)$. In brief, the patients were allowed to eat until midnight on the day before surgery and were required to drink a rehydration solution by 3 hours before surgery. The nasogastric tube was removed immediately after surgery. The oral intake was initiated on postoperative day (POD) 1 , beginning with water and an oral nutritional supplement. The patients began to eat solid food on POD 2, starting with rice gruel and soft food on POD 3 and advancing in three steps to regular food intake on POD 7. The patients were discharged when they had achieved adequate pain relief and soft food intake and exhibited normal laboratory data on POD 7. No postoperative medications to increase appetite, bowel movement or nutrition supplement were used for patients in this study. Furthermore, in the present study, although all of the patients received the same aftercare, including a physical examination and laboratory tests, in the first 3 months after surgery at the outpatient clinic, the patients did not receive any oral nutrition supplements to help them avoid lean mass loss.

Body composition analysis. The segmental body composition was analyzed using a Tanita MC-190EM bioelectrical impedance analyzer (Tanita, Tokyo, Japan), which provides relative information 
Table II. Surgical and pathological outcomes after gastrectomy.

\begin{tabular}{|c|c|c|c|c|}
\hline & $\begin{array}{l}\text { All cases } \\
(\mathrm{N}=888)\end{array}$ & $\begin{array}{l}\text { Without complications } \\
\qquad(\mathrm{N}=732)\end{array}$ & $\begin{array}{l}\text { With complications } \\
\qquad(\mathrm{N}=156)\end{array}$ & $p$-Value \\
\hline \multicolumn{5}{|c|}{ Lymph node dissection, $\mathrm{n}(\%)$} \\
\hline D1+ dissection & $533(60.0)$ & $451(50.8)$ & $82(52.6)$ & \multirow[t]{2}{*}{0.134} \\
\hline D2 dissection & $355(40.0)$ & $281(49.2)$ & $74(47.4)$ & \\
\hline \multicolumn{5}{|c|}{ Type of gastrectomy, n (\%) } \\
\hline Distal & $557(62.7)$ & $482(65.8)$ & $75(48.1)$ & \multirow[t]{3}{*}{0.001} \\
\hline Total & $309(34.8)$ & $234(32.0)$ & $75(48.1)$ & \\
\hline Other & $22(2.5)$ & $16(2.2)$ & $6(3.8)$ & \\
\hline \multicolumn{5}{|c|}{ Type of approach, n (\%) } \\
\hline Conventional & $457(51.5)$ & $371(50.7)$ & $86(55.1)$ & \multirow[t]{2}{*}{0.457} \\
\hline Laparoscopic & $431(48.5)$ & $361(49.3)$ & $70(44)$. & \\
\hline \multicolumn{5}{|l|}{ Bleeding, $g$} \\
\hline Median (range) & $130(5-3780)$ & $120(5-2510)$ & $245(5-3780)$ & 0.001 \\
\hline \multicolumn{5}{|c|}{ Operative time, $\min$} \\
\hline Median (range) & $186(66-585)$ & $183(66-402)$ & $203(88-585)$ & 0.001 \\
\hline \multicolumn{5}{|c|}{ Pathological T factor, $\mathrm{n}(\%)$} \\
\hline $\mathrm{T} 0-\mathrm{T} 1$ & $620(69.8)$ & $440(60.1)$ & $100(64.1)$ & \multirow[t]{4}{*}{0.170} \\
\hline $\mathrm{T} 2$ & $101(11.4)$ & $87(11.9)$ & $23(14.7)$ & \\
\hline $\mathrm{T} 3$ & $85(9.6)$ & $86(11.7)$ & $20(12.9)$ & \\
\hline $\mathrm{T} 4$ & $82(9.2)$ & $119(16.3)$ & $13(8.3)$ & \\
\hline \multicolumn{5}{|c|}{ Pathological N factor, n (\%) } \\
\hline No & $519(58.4)$ & $440(60.1)$ & $79(50.6)$ & \multirow[t]{4}{*}{0.168} \\
\hline N1 & $109(12.3)$ & 87 (11.9) & $22(14.1)$ & \\
\hline $\mathrm{N} 2$ & $111(12.5)$ & $86(11.7)$ & $25(16.0)$ & \\
\hline N3 & $149(16.8)$ & $119(16.3)$ & $30(19.3)$ & \\
\hline
\end{tabular}

regarding the amount of lean and fat tissue in the trunk area and each limb, as well as the overall body composition and hydration status. The body weight and composition were evaluated by a bioelectrical impedance analyzer within 1 week before surgery, and at 1 week, 1 month and 3 months after surgery.

Evaluation of operative morbidity and mortality. Surgical and nonsurgical complications were assessed prospectively and classified according to the Clavien-Dindo classification (16). Operative mortality was defined as postoperative death from any cause within 30 days after surgery or during the same hospital stay.

Data evaluation, statistical analyses, and ethics. The values are expressed as the median and range. The statistical analyses were performed using the chi-square test or Wilcoxon's signed-rank test. A $p$-value of less than 0.05 was considered to indicate statistical significance. The SPSS software package (v12.0 J Win; SPSS, Chicago, IL, USA) was used for all statistical analyses. The R-category and extent of dissection were determined by the Japanese Classification of Gastric Carcinoma (17), third English edition and the Japanese Gastric Cancer Association guidelines (18). The study was approved by the Institutional Review Board of Kanagawa Cancer Center.

\section{Results}

Background characteristics. A total of 888 patients were eligible for the present study. The median age was 68 years (range $=27-90$ years). Five-hundred and ninety-five patients were male, and 293 were female. Seven hundred and fortytwo patients were classified as not having any surgical complications and 156 as having surgical complications. The background characteristics of the patients are summarized in Table I. The median age was significantly higher, the American Society of Anesthesiology score significantly worse, and the incidence of male patients, hypertension, and smoking habit significantly higher in the group with complications than in the group without $(p=0.002, p=0.026$, $p=0.036$, and $p=0.018$, respectively). Furthermore, the preoperative total body weight and lean body mass were significantly higher in the group with complications ( $p=0.011$ and $p=0.010$, respectively). The operative details and pathological findings are shown in Table II. The incidence of total gastrectomy was higher in the group with complications. The median blood loss and median operative time were also much greater in the group with complications (both $p<0.001$ ). The median length of hospital stay (LOS) was 8 days in the group without complications and 12 days in the group with, showing a significant difference $(p=0.001)$.

Postoperative surgical complications. The details of the postoperative surgical complications are shown in Table III. The overall complication rate was $17.6 \%$ in the present study. Pancreatic fistula and anatomic leakage were the most 


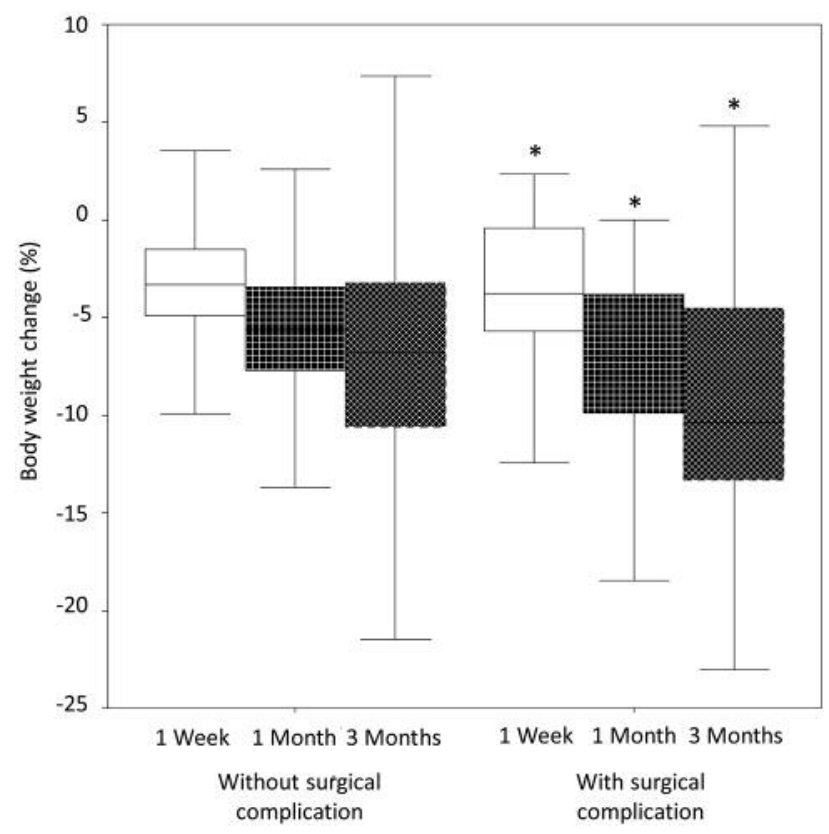

Figure 1. A comparison of changes in body weight after gastrectomy between the patients who had postoperative surgical complications and those who did not. Significantly different from the group without complications at $* p<0.001$ and ${ }^{\#} p=0.002$.

Table III. Details of surgical complications after gastrectomy.

\begin{tabular}{lcc}
\hline Complication & $\begin{array}{c}\text { Grade 2 or more } \\
(\mathrm{N}=156), \mathrm{n}(\%)\end{array}$ & $\begin{array}{c}\text { Grade 3 or more } \\
(\mathrm{N}=62), \mathrm{n}(\%)\end{array}$ \\
\hline Pancreatic fistula & $38(24.3)$ & $6(9.7)$ \\
Abdominal abscess & $14(9.0)$ & $10(16.1)$ \\
Anastomotic leakage & $31(19.9)$ & $25(40.3)$ \\
Anastomotic stenosis & $8(5.1)$ & $8(12.9)$ \\
Ileus & $20(12.8)$ & $13(20.0)$ \\
Pneumonia & $23(14.7)$ & $2(3.2)$ \\
Postoperative bleeding & $8(5.1)$ & $2(3.2)$ \\
Wound abscess & $9(5.8)$ & $1(1.6)$ \\
Pleural effusion & $4(2.6)$ & $1(1.6)$ \\
Other & $21(13.5)$ & $10(16.1)$ \\
\hline
\end{tabular}

frequently diagnosed complications of grade 2 or more severity. Among surgical complications of grade 3 or more, anatomic leakage and ileus were the most frequently diagnosed.

Body composition. The rate of loss of body weight for the whole cohort at 1 week, 1 month, and 3 months was $3.4 \%$ $($ range $=14.6-7.2 \%), 6.1 \% \quad($ range $=23.7-5.9 \%)$, and $8.3 \%$ (range=26.6-7.3\%), respectively. Figure 1 shows a comparison of the loss of body weight between the groups

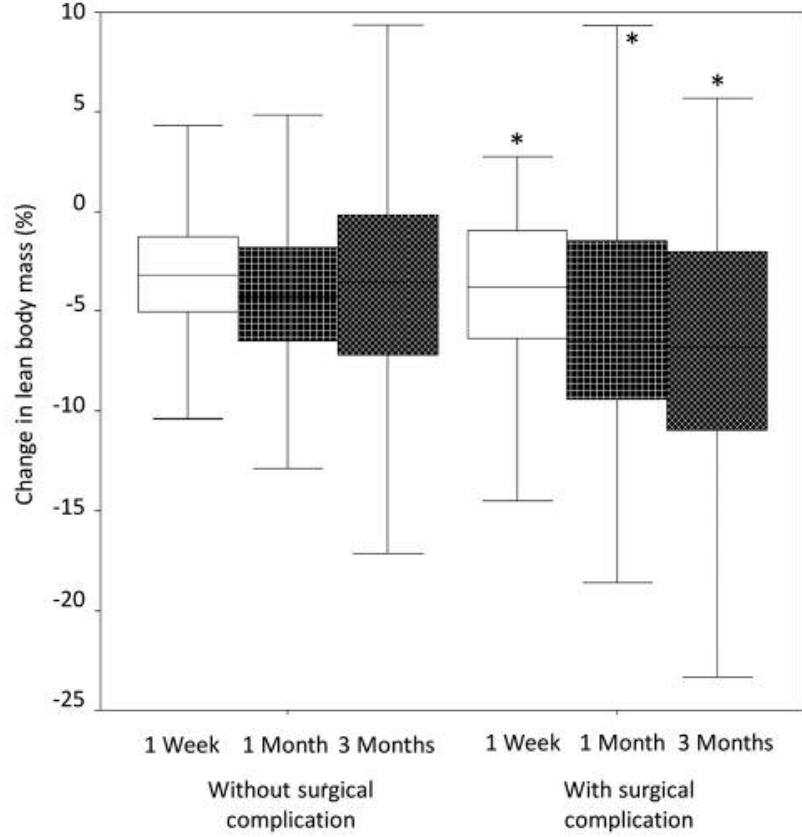

Figure 2. A comparison of the changes of lean body mass after gastrectomy between the patients who had postoperative surgical complications and those who did not. *Significantly different from the group without complications at $p<0.001$.

with and without complications at 1 week to 3 months. Significant decreases were observed at 1 week to 3 months in the group with complications $(p<0.001, p=0.002$ and $p<0.001$, respectively).

The rates of loss of lean body mass for the whole cohort at 1 week, 1 month, and 3 months were $3.5 \%$ (range $=27.0$ $26.1 \%), 4.8 \%($ range $=20.2-17.3 \%)$, and $4.9 \%($ range $=23.3-$ $24.9 \%$ ), respectively. Figure 2 shows a comparison of the loss of lean body mass between $\mathrm{NC}$ and $\mathrm{C}$ group at 1 week to 3 months. Significant differences were observed at 1 week to 3 months $(p<0.001, p=0.001$, and $p<0.001$, respectively).

\section{Discussion}

The aim of the present study was to compare the degree and duration of body composition changes between patients with and without surgical complications after gastrectomy. The major finding was that decreases in both the body weight and lean body mass after gastrectomy were significantly more serious in patients with surgical complications than in those without. Our results suggest that additional care or treatment might be needed to maintain lean body mass after gastrectomy in patients with surgical complications.

The drivers of loss of body weight and lean body mass are multifactorial, with systemic inflammation, physical inactivity, 
and a reduced nutrient intake all contributing. Once stresses due to surgery or surgical complications occur, immune cells produce cytokines that act as mediators of both immune and systemic responses to injury. Cytokines, such as interleukin 6 , interleukin 1 and tumor necrosis factor, are synthesized from amino acids supplied by muscle catabolism. In addition, the response of skeletal muscle during critical illness is characterized by a rapid decrease in protein content and accelerated amino acid release (19). Hassen et al. demonstrated that negative associations existed between the skeletal muscles mass and systemic inflammatory response syndrome score after surgery in 33 major vascular surgery patients (20). In addition, Iida et al. reported that postoperative muscle weakness was associated with interleukin- 6 production immediately after cardiac surgery in 154 consecutive patients who had undergone coronary artery bypass grafting (21). Therefore, surgical stress due to surgical complications might affect the loss of body weight and lean body mass after surgery. In addition, surgical complications are reported to increase the LOS. A previous study showed that lean body mass loss was associated with an increased LOS. In the present study, the median LOS in patients who had surgical complications after gastrectomy was also significantly longer than in those without such complications. Therefore, a longer LOS due to surgical complications might also affect the loss of body weight and lean body mass.

Many trials evaluated the effects of early nutritional support on postoperative body weight loss and postoperative lean body mass in patients with gastric cancer who underwent gastrectomy $(22,23)$. However, few have described any positive effects of early nutritional support on postoperative body composition changes after gastrectomy. One possible reason for this failure to show such effects might be that previous trials did not take into consideration the influence of postoperative surgical complications on postoperative body composition changes. For example, Ida et al. conducted a prospective randomized phase III trial that evaluated whether or not the perioperative administration of an eicosapentaenoic acid (EPA)-enriched supplement could prevent body weight loss after total gastrectomy for gastric cancer (22). Unfortunately, a standard diet with EPA-enriched immunonutrition did not help prevent body weight loss after total gastrectomy. In their study, about $15 \%$ patients with postoperative surgical complications were included in the analysis. In contrast, Hatao et al. investigated the effects of oral nutritional supplement administration on postoperative body weight loss in patients with gastric cancer who had undergone total or distal gastrectomy (23). They demonstrated that oral nutritional supplementation after total gastrectomy significantly prevented postoperative weight loss. In that study, patients who had postoperative surgical complications were excluded from the analysis. These previous findings suggest that postoperative surgical complications might have had some clinical influence on the outcomes. Therefore, postoperative surgical complications might need to be considered as a factor for stratification in future phase III trials evaluating the effects of nutritional treatment for gastric cancer.

Several limitations associated with the present study warrant mentioning. Firstly, the present study was a retrospective analysis performed at a single institution. The results need to be confirmed in another cohort or in a prospective multicenter study. Secondly, we failed to measure the total calorie intake, physical activity, or serum markers after surgery in the present study. The influence of calorie intake and physical activity on postoperative body composition changes was therefore unclear in the present study.

In conclusion, decreases in body weight and lean body mass after gastrectomy were more serious in the patients with surgical complications than in those without surgical complications. In order to maintain body weight and lean body mass among patients with surgical complications, additional care or treatments are needed

\section{Ethics Approval and Consent to Participate}

The study was approved by the Institutional Review Board of Kanagawa Cancer Center. The study was conducted in accordance with the Declaration of Helsinki. All subjects signed consent forms.

\section{Consent to Publish}

The study does not involve any personal identifiable data.

\section{Availability of Data and Materials}

Data and materials are available to any researcher interested upon reasonable request to the corresponding author.

\section{Competing Interests}

The Authors declare no competing interests in association with the present study.

\section{Funding}

None.

\section{Acknowledgements}

This work was supported, in part, by the non-governmental organization Kanagawa Standard Anti-cancer Therapy Support System. The authors express their sincere gratitude to Mrs. Natsumi Sato and Mrs. Rika Takahashi for their excellent data management in this study.

\section{References}

1 Torre LA, Bray F, Siegel RL, Ferlay J, Lortet-Tieulent J and Jemal A: Global cancer statistics 2012. CA Cancer J Clin 65: 87$108,2015$. 
2 Yoshikawa T, Rino Y, Yukawa N, Oshima T, Tsuburaya A and Masuda M: Neoadjuvant chemotherapy for gastric cancer in Japan: A standing position by comparing with adjuvant chemotherapy. Surg Today 44: 11-21, 2014.

3 Aoyama $\mathrm{T}$ and Yoshikawa T: Adjuvant therapy for locally advanced gastric cancer. Surg Today 47: 1295-1302, 2017.

4 Sano T, Sasako M, Mizusawa J, Yamamoto S, Katai H, Yoshikawa $\mathrm{T}$, Nashimoto A, Ito $\mathrm{S}$, Kaji $\mathrm{M}$, Imamura $\mathrm{H}$, Fukushima N, Fujitani K and Stomach Cancer Study Group of the Japan Clinical Oncology Group: Randomized controlled trial to evaluate splenectomy in total gastrectomy for proximal gastric carcinoma. Ann Surg 265: 277-283, 2017.

5 Sasako M, Sano T, Yamamoto S, Kurokawa Y, Nashimoto A, Kurita A, Hiratsuka M, Tsujinaka T, Kinoshita T, Arai K, Yamamura Y, Okajima K and Japan Clinical Oncology Group: D2 lymphadenectomy alone or with para-aortic nodal dissection for gastric cancer. N Engl J Med 359: 453-462, 2008.

6 Sasako M, Sano T, Yamamoto S, Sairenji M, Arai K, Kinoshita T, Nashimoto A, Hiratsuka M and Japan Clinical Oncology Group (JCOG9502): Left thoracoabdominal approach versus abdominal-transhiatal approach for gastric cancer of the cardia or subcardia: a randomised controlled trial. Lancet Oncol 7: 644651, 2006

7 Hayashi T, Yoshikawa T, Aoyama T, Hasegawa S, Yamada T, Tsuchida K, Fujikawa H, Sato T, Ogata T, Cho H, Oshima T, Rino Y and Masuda M: Impact of infectious complications on gastric cancer recurrence. Gastric Cancer 18: 368-374, 2015.

8 Sierzega M, Kolodziejczyk P and Kulig J: Impact of anastomotic leakage on long-term survival after total gastrectomy for carcinoma of the stomach. Br J Surg 97: 1035-1042, 2010.

9 Adams JF: The clinical and metabolic consequences of total gastrectomy. I: Morbidity, weight, and nutrition. Scand J Gastroenterol 2: 137-149, 1967.

10 Fein M, Fuchs KH, Thalheimer A, Freys SM, Heimbucher J and Thiede A: Long-term benefits of Roux-en-Y pouch reconstruction after total gastrectomy: A randomized trial. Ann Surg 247: 759765,2008

11 Aoyama T, Yoshikawa T, Shirai J, Hayashi T, Yamada T, Tsuchida K, Hasegawa S, Cho H, Yukawa N, Oshima T, Rino Y, Masuda M and Tsuburaya A: Body weight loss after surgery is an independent risk factor for continuation of S-1 adjuvant chemotherapy for gastric cancer. Ann Surg Oncol 20: 2000-2006, 2013.

12 Aoyama T, Sato T, Maezawa Y, Kano K, Hayashi T, Yamada T, Yukawa N, Oshima T, Rino Y, Masuda M, Ogata T, Cho H and Yoshikawa T: Postoperative weight loss leads to poor survival through poor S-1 efficacy in patients with stage II/III gastric cancer. Int J Clin Oncol 22: 476-483, 2017.

13 Aoyama T, Kawabe T, Fujikawa H, Hayashi T, Yamada T, Tsuchida K, Yukawa N, Oshima T, Rino Y, Masuda M, Ogata T, Cho H and Yoshikawa T: Loss of lean body mass as an independent risk factor for continuation of S-1 adjuvant chemotherapy for gastric cancer. Ann Surg Oncol 22: 2560-2566, 2015.
14 Yamada T, Hayashi T, Cho H, Yoshikawa T, Taniguchi H, Fukushima R and Tsuburaya A: Usefulness of enhanced recovery after surgery protocol as compared with conventional perioperative care in gastric surgery. Gastric Cancer 15: 34-41, 2012.

15 Yamada T, Hayashi T, Aoyama T, Shirai J, Fujikawa H, Cho H, Yoshikawa T, Rino Y, Masuda M, Taniguchi H, Fukushima R and Tsuburaya A: Feasibility of enhanced recovery after surgery in gastric surgery: A retrospective study. BMC Surg 14: 41, 2014.

16 Dindo D, Demartines N and Clavien PA: Classification of surgical complications: a new proposal with evaluation in a cohort of 6336 patients and results of a survey. Ann Surg 240: 205-213, 2004.

17 Japanese Gastric Cancer Association: Japanese Classification of Gastric Carcinoma: 3rd English Edition. Gastric Cancer 14: 101$112,2011$.

18 Japanese Gastric Cancer Association: Japanese gastric Cancer Treatment Guidelines 2010 (ver 3). Gastric Cancer 14: 113-123, 2011.

19 Cruickshank AM, Fraser WD, Burns HJ, Van Damme J and Shenkin A: Response of serum interleukin-6 in patients undergoing elective surgery of varying severity. Clin Sci 79: 161-165, 1990.

20 Hassen TA, Pearson S, Cowled PA and Fitridge RA: Preoperative nutritional status predicts the severity of the systemic inflammatory response syndrome (SIRS) following major vascular surgery. Eur J Vasc Endovasc Surg 33: 696-702, 2007.

21 Iida Y, Yamada S, Nishida O and Nakamura T: Body mass index is negatively correlated with respiratory muscle weakness and interleukin-6 production after coronary artery bypass grafting. J Crit Care 25: 172, e1-8, 2010.

22 Ida S, Hiki N, Cho H, Sakamaki K, Ito S, Fujitani K, Takiguchi N, Kawashima Y, Nishikawa K, Sasako M, Aoyama T, Honda M, Sato T, Nunobe S and Yoshikawa T: Randomized clinical trial comparing standard diet with perioperative oral immunonutrition in total gastrectomy for gastric cancer. Br J Surg 104: 377-383, 2017.

23 Hatao F, Chen KY, Wu JM, Wang MY, Aikou S, Onoyama H, Shimizu N, Fukatsu K, Seto Y and Lin MT: Randomized controlled clinical trial assessing the effects of oral nutritional supplements in postoperative gastric cancer patients. Langenbecks Arch Surg 402: 203-211, 2017. 